\title{
ELEIÇÕES DIRETAS AO PARLASUL NA ARGENTINA E NO PARAGUAI: DA REPRESENTAÇÃO PARLAMENTAR NA INTEGRAÇÃO À CONFORMAÇÃO ELEITORAL REGIONAL NA ESFERA DOMÉSTICA
}

\author{
DIRECT ELECTIONS TO PARLASUL IN ARGENTINA AND PARAGUAY: FROM \\ PARLIAMENTARY REPRESENTATION TO INTEGRATION WITH THE REGIONAL
}

ELECTORAL CONFORMATION IN THE DOMESTIC SPHERE

\author{
Matheus Felipe Silva ${ }^{1}$ \\ Universidade Estadual Paulista, Araraquara, Brasil
}

\begin{abstract}
Resumo: O presente artigo busca uma reflexão acerca do processo de adequação das legislações eleitorais da Argentina e do Paraguai para a realização de eleições diretas ao Parlasul, atendendo as demandas do seu Protocolo Constitutivo. Considera-se importante observar a participação das delegações nacionais desde a formação de instâncias parlamentares no Mercosul, nas quais foram negociados os progressos na conformação de um parlamento regional. Esses períodos podem ser apreendidos por análises bibliográficas, a fim de compreender a mobilização das delegações dos dois países até o momento de conformação do Parlasul. Esses elementos são utilizados para traçar paralelos com as mobilizações nacionais em torno da conformação de ditas eleições e os resultados das mesmas, buscando continuidades e elementos influenciadores em todo o processo.
\end{abstract}

Palavras-Chave: Parlamento do Mercosul; Eleições regionais; Argentina; Paraguai.

\begin{abstract}
This article seeks a reflection on the process of adaptation of the electoral laws in Argentina and Paraguay in order to have direct elections of Mercosur parliamentarians, taking into account the demands of its Constitutive Protocol. It is important to note the participation of the national delegations since the formation of parliamentary bodies in Mercosur, in which progress has been negotiated in the formation of a regional parliamentary instances. These periods can be apprehended by bibliographical analyzes to understand the mobilization of the delegations of the two countries until the moment of formation of Parlasul. These elements are used to draw parallels with the national mobilizations around the conformation of said elections and the results these, searching for continuities and influential elements throughout the process.
\end{abstract}

Keywords: Mercosur Parliament; Regional elections; Argentina; Paraguay.

1 Mestrando pelo Programa de Pós-Graduação em Ciências Sociais da Faculdade de Ciências e Letras de Araraquara UNESP/FCLAr. Pesquisador do Grupo de Estudos Interdisciplinares de Cultura e Desenvolvimento (GEICD) e da Rede de Pesquisa em Política Externa e Regionalismo (REPRI). Email: matheusfstety@yahoo.com.br. 


\section{INTRODUÇÃO}

$\mathrm{Na}$ década de 60, houve a chamada primeira onda regionalista, da qual o arranjo europeu é o exemplo mais notório. Esse movimento pode ser caracterizado por alto grau de institucionalização para a integração econômica e resolução política de conflitos (HURREL, 1995, p. 23). O fenômeno afetou outras regiões, em diferentes graus, especialmente a América Latina.

A alta burocratização e maior institucionalização dessa primeira onda influenciou a criação da Associação Latino-Americana de Livre Comércio (ALALC). Esse grupo surge da assinatura do Tratado de Montevidéu, firmado em 18 de fevereiro de 1960 na cidade de Montevidéu, Uruguai. Sua premissa era ser um modelo de integração regional que buscasse aumentar a interdependência dos países latinoamericanos, a fim de criar uma zona de livre comércio na região (KINOSHITA, 2002).

No regionalismo dos anos 80 e 90, emerge o denominado "novo regionalismo" ou "regionalismo aberto" (CEPAL, 1994), caracterizado como "um instrumento de inserção competitiva no mercado globalizado" (CASTRO, 2011, p. 14). Assim, "busca-se aliar a interdependência promovida 'de fato' pela ação do mercado àquela decorrente de acordos de preferências comerciais" (CASTRO, 2011, p. 14). O Mercosul surge como uma tentativa de criação de uma área de livre comércio no Cone Sul da América Latina, iniciado em 1991 pela assinatura do Tratado de Assunção, por quatro membros fundadores: Argentina, Brasil, Uruguai e Paraguai.

O regionalismo Sul-Americano é caracterizado pela lógica intergovernamentalista, no qual os Executivos nacionais dominam as instâncias Executivas dos blocos regionais e, por isso, definem as agendas da integração. Naturalmente, há questionamentos quanto à despolitização dos arranjos de mercado comum (CAPORASO, 1998). A questão acerca do déficit democrático na integração regional abarca a legitimidade do processo, do nível de accontability oferecidos pelos Estados a suas populações no processo de integração (MARIANO, 2013).

O chamado déficit democrático relaciona-se ao grau reduzido da participação popular ou de setores da sociedade, como associações e organizações sindicais. As amplas pautas econômicas e o protagonismo dos Executivos nacionais, que ocupam e monopolizam as esferas decisivas dos blocos, despolitizam o processo, restringem a 
participação social, limitam as agendas programáticas da integração e afastam essa última da vida cotidiana das populações nacionais (LUCIANO; MARIANO, 2012). Observando o caso da União Europeia, seria possível indicar uma "deficiência de legitimação" (HABERMAS, 2013) em seu processo de integração.

O parlamento regional é fundamental nesse processo de superação do déficit democrático, tendo em vista seu caráter representativo. A realização de eleições diretas para parlamentares regionais foi a ferramenta introduzida pela União Europeia em seu parlamento regional, o Parlamento Europeu e, a partir de então, serviu de exemplo para outros processos de integração regional.

O Parlamento Europeu, que já figurava no Tratado de Roma de 1957 como instituição responsável por representar as populações no processo de integração, passa a adotar um sistema de representação proporcional das populações em 1979 e, em 1999, realiza as primeiras eleições europeias simultâneas em todos os países-membros para o Parlamento Europeu (MALAMUD; SOUSA, 2005). Dessa forma, esses parlamentares regionais seriam efetivamente escolhidos por suas respectivas populações e teriam a legitimidade para atuar pelo interesse dos cidadãos dentro da integração.

Segundo Maira (2013), o surgimento dos parlamentos regionais vem ainda da busca por melhorias no estabelecimento e cumprimento de acordos de cooperação e integração, o que é verificado tanto para o caso europeu quanto latino-americano. Sua origem e funcionamento pressupõem uma revisão nos conceitos de soberania e legitimidade, tanto na atuação dos Estados nacionais em seu contexto doméstico quanto regional, tendo em vista há inequivocamente, dentro dos processos de integração, transferência de poderes e competências à esfera regional.

Esse é um ponto importante que explica a lentidão dos acordos de integração regional e seu processo gradual de aplicação, uma vez que existe forte resistência de alguns dos setores nacionais, como forças políticas e meios de comunicação, a esse processo de reconfiguração dos poderes e competências nacionais frente às novas instituições regionais.

Ressaltam Bressan, Mariano e Luciano (2015) que as instâncias parlamentares nos processos de integração visam solucionar o deficit democrático na medida em que inicialmente apresentam um caráter representativo. Ou seja, os 
parlamentares que integram determinado órgão passaram, previamente, por critérios nacionais de legitimação representativa, mas sem que necessariamente haja alguma especificidade para que essa legitimidade seja estendida a esferas não domésticas.

Nesse sentido, a representação inter ou supranacional que passa pela legitimação direta na esfera nacional por vias eleitorais é aquela que melhor pode lidar com a problemática do déficit democrático do processo de integração regional, visto que a representação por eleições diretas é aquela que designa parlamentares exclusivos às atividades exteriores.

No entanto, nesse processo de criação de instâncias parlamentares em arranjos de integração regional, abre-se a possibilidade de choques diretos com posições de atores políticos nacionais, especialmente no que concerne à internacionalização de regras emanadas das esferas regionais. A criação do Parlamento do Mercosul (Parlasul) foi negociada dentro da Comissão parlamentar Conjunta (CPC), compostas por bancadas dos 4 membros fundadores.

Posteriormente, os acordos em torno do Protocolo Constitutivo do Parlasul foram remetidos aos Congressos Nacionais, para sua ratificação. Esse documento seria a base para que os membros do Parlasul organizassem eleições diretas de suas bancadas ao órgão, mas o processo legislativo a ditas votações seguiu cursos peculiares dentro de cada país.

De forma mais breve, "o Parlasul, de acordo com seu Protocolo Constitutivo, é composto por representantes dos Estados-membros, diretamente eleitos pelos seus cidadãos, com base em legislação eleitoral nacional" (LUCIANO, 2012, p. 53). O estabelecimento do Protocolo e seus desdobramentos guardam relações anteriores ao Parlasul, além de interferir na atividade legislativa nacional, especialmente pela conformação de suas eleições diretas nas esferas domésticas.

Dessa forma, o presente artigo trata da realização de eleições nacionais ao Parlasul no Paraguai e na Argentina, únicos países que as realizam. Para isso, são observados os comportamentos das bancadas dos dois países desde a CPC, onde foi negociado o Protocolo Constitutivo do Parlasul, seguindo para uma análise de como cada um desses países organizou essas eleições e os resultados destas. A proposta é buscar possíveis conexões entre os comportamentos apresentados desde a CPC até a 
realização das eleições ao Parlasul, compreendendo se e o quanto essas experiências pretéritas perduram e influenciam o resultado dessas eleições.

Também é observado se essas eleições atendem às prerrogativas do Protocolo Constitutivo do Parlasul e quais as possibilidades apresentadas, mediante aos contextos apresentados nesses dois países, à conformação do "Dia do Mercosul Cidadão”, quando as eleições ao Parlasul acontecerão simultaneamente em todos os seus países membro.

\section{A COMISSÃO PARLAMENTAR CONJUNTA CPC}

A primeira instância parlamentar surgida na integração no Cone Sul da América Latina precede a própria criação do Mercosul em 1991, pelo Tratado de Assunção. O Tratado de Integração Cooperação e Desenvolvimento, celebrado por Argentina e Brasil em 29 de novembro de 1988, estabeleceu o Programa de Integração

e Cooperação Econômica (PICE) e instituiu a Comissão Parlamentar Conjunta de Integração (CPCI).

Sua criação não derivou de demandas parlamentares por participação no nascente processo de integração, mas derivou do cálculo pragmático dos Executivos que, ao firmarem o Programa, buscaram uma instância que tivesse com atuação limitada junto aos Congressos Nacionais na implementação de acordos das esferas da integração, composta por 12 legisladores nacionais para mandatos simultâneos de dois anos (MARIANO, 2011).

A Comissão Parlamentar do Mercosul (CPC) tem sua origem nas queixas dos Presidentes das Comissões de Relações Exteriores da Câmara dos Deputados e do Senado dos quatro parlamentos nacionais, que pressionaram pela criação de uma instância com prerrogativa de canal de comunicação entre os Poderes Executivos e os parlamentos dentro do Tratado de Assunção de 1991 (DRUMMOND, 2010).

Apenas na III Reunião de Parlamentares do Mercosul o seu regimento interno foi estabelecido. Importam duas observações: a composição de 16 parlamentares por delegação, escolhidos dentro dos Congressos Nacionais e as prerrogativas da Comissão, basicamente as mesmas da CPCI, de acelerar internacionalização de regras 
nos Legislativos nacionais e harmonizar legislações para conformidades com as determinações da integração.

\section{AS NEGOCIAÇÕES DO PARLASUL NA CPC E SUA TRANSIÇÃO}

A criação do Parlasul a partir de seu Protocolo Constitutivo foi gestado na CPC que, em 1996, em reunião com uma delegação do Parlamento Europeu, considerou necessário o início de estudos técnicos que encaminhassem a criação de uma Assembleia Parlamentar no Mercosul, sendo que em 2000 as representações argentina e brasileira apresentaram cronogramas para a institucionalização do Parlamento do Mercosul (DRUMMOND, 2010).

Desse modo, era necessário estabelecer o Protocolo Constitutivo tendo em vista o consenso entre as delegações da CPC. O Protocolo foi negociado entre 2003 e 2004 em torno das propostas da Argentina e do Brasil apresentadas na CPC, para que fossem inseridas questões mais técnicas pelo Grupo Técnico de Alto Nível (GTAN) à proposta final, remetida em 2005 à Comissão Mercado Comum (CMC).

A primeira década dos anos 2000 teve um contexto de convergência de propostas à integração por parte dos Executivos nacionais do período chamada de giro à esquerda. Os rumos para o aprofundamento da integração, no entanto, apresentavam divergências. Se os governos Lula e Kirchner advogavam pela integração no Mercosul com a conformação de um Parlamento regional, tanto o Executivo nacional quanto a representação paraguaia na $\mathrm{CPC}$, insistiam na necessidade de um fortalecimento à Comissão antes de negociar um parlamento regional.

Em 2003, as delegações brasileiras e argentina apresentaram anteprojetos de Protocolos Constitutivos que seriam debatidos para a deliberação de uma versão final a ser consensuada dentro da CPC no ano de 2004 (PIETRAFESA, 2009). A delegação paraguaia não concordava com os termos propostos e nem mesmo com a formação de um parlamento regional. Eram três as principais reivindicações da delegação: fortalecimento da CPC, decisões por consenso e paridade no número de parlamentares.

Este posicionamento alterou-se apenas em 2005, quando, após eleições no Uruguai, a delegação ficou isolada na resistência ao Parlasul (PIETRAFESA, 2009) e percebendo a necessidade de também participar do processo negociador, viabilizou a 
conformação do Protocolo com as suas posições contrárias que figuraram como disposições transitórias.

Em 2005, os presidentes da Comissão Parlamentar Conjunta organizaram a GTAN para que esta finalizasse o texto do Protocolo Constitutivo em torno dos consensos estabelecidos na CPC até então, sendo remetido e aprovado pelo CMC no mesmo ano (DRUMMOND, 2010). A aprovação dos termos do Protocolo foi aprovada por parlamentares de todas as delegações, mas interessa indicar os representantes da delegação paraguaia, o senador Alfonso Gonçales Nuñez (Partido Colorado, ANR) e o senador Roberto Luis Guggiari (Partido Liberal Radical Autêntico, PLRA) (PIETRAFESA, 2009).

O ano de 2006 foi o período no qual os Congressos Nacionais discutiram e ratificaram o Protocolo Constitutivo. As regras da proporcionalidade seriam estabelecidas até 2007 pelo CMC, ano em que as atividades no Parlasul tiveram início. No entanto, o então senador paraguaio Alfonso González Nuñez apresentou o projeto para que o país realizasse eleições diretas ao Parlasul em 2007.

O projeto foi aprovado ainda em 2006 pelo Senado, sendo também aprovado pela Câmara dos Deputados no início do ano seguinte e posteriormente promulgado pela presidência em Paraguai na lei $\mathrm{n}^{\mathrm{o}} 3.166 / 07$ para eleger 18 parlamentares. Essa atitude unilateral paraguaia visou a garantia de um número considerado razoável para sua delegação. Por outro lado, o país foi criticado. Ainda assim, o número de 18 parlamentares foi utilizado como piso para a primeira fase e para o cálculo de proporcionalidade atenuada à representação, dadas as disparidades populacionais dos membros do Parlasul.

O Acordo Político para a Consolidação do Mercosul e Proposições Correspondentes de 28 de abril de 2009 foi o marco no qual foram definidos os termos da representação proporcional. Foi definido que

Os países com população de até quinze milhões de habitantes recebem o piso de dezoito cadeiras; os países com até quarenta milhões de habitantes farão jus a uma cadeira por milhão de habitantes acima dos quinze iniciais; a partir de quarenta até oitenta milhões, há o acréscimo de uma cadeira adicional para cada dois milhões e quinhentos habitantes; de oitenta a cento e vinte milhões, acrescentase uma cadeira para cada cinco milhões de habitantes adicionais; acima de cento e vinte milhões de habitantes, acréscimo de uma cadeira para cada dez milhões de habitantes adicionais. O Acordo estabelece que até 2014, quando finda a segunda fase da transição, a 
Argentina e o Brasil elegerão 26 e 37 representantes, respectivamente, que corresponde a um terço da diferença entre o piso (18) e o número máximo atribuído a cada um desses Estados Partes. Contudo, caso se verifique a adesão de novo Estado Parte ao Mercosul, a Argentina e o Brasil poderão eleger o número total de representantes a que têm direito nas eleições seguintes que venham a se realizar. Por conseguinte, a partir de 2014 ou a partir do momento em que a Venezuela deixe a sua condição de Estado Parte em processo de adesão para tornar-se membro pleno do Mercosul, as bancadas ficarão assim compostas: a Argentina, com 39,3 milhões de habitantes, terá quarenta e três parlamentares (vinte e seis, até 2014); o Brasil, com 192,6 milhões, terá setenta e cinco (trinta e sete, até 2014); o Paraguai, com 6,1 milhões e o Uruguai, com 3,3 milhões de habitantes, terão dezoito parlamentares cada (DRUMMOND, 2010, p. 361).

Contemplando as divergências em relação às eleições e proporcionalidades, o Protocolo Constitutivo continha disposições transitórias que passariam por revisão posteriormente, para a construção de um consenso. Outro elemento importante foi o estabelecimento do Parlasul por etapas.

$\mathrm{Na}$ primeira, até 2010, todas as delegações teriam 16 membros eleitos indiretamente pelos Congressos Nacionais até que fossem estabelecidos os critérios da representação cidadã (LUCIANO, 2012). Na segunda, de 2011 a 2014, os países elegeriam diretamente seus representantes ao Parlasul de acordo com regras nacionais próprias enquanto era estabelecido o Dia do Mercosul Cidadão, que passaria a valer na etapa seguinte (pós 2014) com eleições diretas e unificadas em todos os países membro (LUCIANO, 2012). A tabela a seguir mostra o resultado final das etapas transitórias e suas composições.

\section{Tabela 1: Incorporação da representação cidadã no Parlasul}

\begin{tabular}{lcccc}
\hline Estados-membros & $\begin{array}{c}\text { População } \\
\text { (aproximada em milhões) }\end{array}$ & $\begin{array}{c}\text { Primeira etapa } \\
(2006-2010)\end{array}$ & $\begin{array}{c}\text { Segunda etapa I } \\
(2011-2014)\end{array}$ & $\begin{array}{c}\text { Segunda etapa II } \\
\text { (pós-2014 e adesão da Venezuela) }\end{array}$ \\
\hline Uruguai & 3,3 & 18 & 18 & 18 \\
Paraguai & 6,4 & 18 & 18 & 18 \\
Venezuela & 27,6 & - & - & 31 \\
Argentina & 41,7 & 18 & 26 & 43 \\
Brasil & 203,4 & 18 & 37 & 74 \\
Total & 282,4 & 72 & 99 & 184 \\
\hline
\end{tabular}

Fonte: Luciano (2012, p. 55).

À exceção do caso do Paraguai, que realizou eleições antes mesmo do fechamento de acordos finais e estabelecimento de prazos, as discussões nos congressos 
nacionais avançaram lentamente e os países não cumpriram os prazos à instituição de um Parlasul totalmente eleito por voto popular, distanciando ainda mais as possibilidades do Dia do Mercosul Cidadão.

Os prazos foram prorrogados em três ocasiões: “em 2006, determinou-se que essas eleições ocorreriam até o final de 2010. Quando vislumbrou-se a impossibilidade de cumprir com essa data, o prazo foi prorrogado para 2014 [...]" (MARIANO, 2013, p. 101). A última prorrogação foi no início de 2014, quando o prazo foi estendido até 2020. A Argentina, que ainda não havia adequado sua legislação, foi favorável, mas logrou, ao final do ano, aprovar o projeto de lei que regulamentou as eleições ao Parlasul no país em 2015.

Sobre as eleições diretas de parlamentares da integração, tema que importa a este artigo, o Protocolo Constitutivo do Parlasul organiza mandatos exclusivos de 4 anos com possibilidade reeleição e gozando do que seria a imunidade de expressão na integração (liberdade de expressar os interesses da integração, sem que sejam constrangidos na esfera doméstica por qualquer desacordo com interesses nacionais), eleitos diretamente por sistemas que contemplem adequada representação por gênero, etnias e regiões conforme as realidades de cada Estado (PARLAMENTO DO MERCOSUL, 2005).

\section{ADEQUAÇÕES LEGISLATIVAS E ELEIÇÕES AO PARLASUL NA ARGENTINA E NO PARAGUAI}

O Paraguai foi o primeiro membro a realizar suas eleições diretas ao Parlasul. Logo após a publicação da lei no 3.166/07, o Tribunal Superior de Justiça Eleitoral, TSJE, adequou o código eleitoral de 1966, estabelecido pela lei $\mathrm{n}^{\circ} 834 / 96$. O projeto de lei foi proposto em 2006 pelo então senador Alfonso Gonzalez Nuñez, da ANR, partido majoritário do país. O parlamentar participou da CPC e das negociações em torno do estabelecimento do Parlasul.

A lei $n^{\circ} 3.166 / 07$ trazia 6 modificações ao código eleitoral paraguaio para incluir as eleições dos parlamentares do Parlasul. Suas características mais importantes são as seguintes: as eleições desses parlamentares ocorrem junto às nacionais (salvo alguma modificação em conformidade com novas deliberações do Mercosul), 
organizadas em listas completas de representação proporcional, a mesma regra dos cargos do Legislativo nacional; o emprego do método D'Hondt para a distribuição dos 18 assentos mais um suplente por vaga.

O contexto da apresentação e aprovação do projeto foi o de ruptura interna e enfraquecimento da ANR. Primeiramente, houve dissidência no partido, que posteriormente perdeu o apoio do PLRA. O PLRA conformou a candidatura à vicepresidente de Fernando Lugo, da frente Guasú, para as eleições de 2008.

O TSJE convocou, em 20 de agosto de 2007, eleições gerais para a data de 20 de abril de 2008 pela Resolução n ${ }^{\circ}$ 55/2007 e referendou seus resultados em 23 de maio de 2008, pela Resolução $n^{\circ}$ 58/2008. Em 2013, o país realizou eleições gerais e ao Parlasul pela segunda vez.

Todas as adequações e implementações para viabilizar as eleições regionais no Paraguai guardam pelo menos quatro questões importantes em relação ao Protocolo Constitutivo. A primeira é que as eleições realizadas em listas únicas de distrito único nacional não conseguem atender a pluralidade étnica e regional do país, além de não haver cotas para grupos minoritários, como por exemplo, cotas de gênero. A segunda diz respeito de a fórmula utilizada ser a mesma aplicada à eleição de deputados nacionais.

Esses dois fatores dificultam a construção de eleições ao Parlasul que abarquem a pluralidade populacional e regional, além também de alocá-las dentro das lógicas de disputas partidárias nacionais. $\mathrm{O}$ terceiro aspecto é o fato de as eleições ao Parlasul ocorrerem junto às gerais nacionais, que determinam mandatos de cinco anos.

Nesse sentido, os parlamentares da integração do Paraguai exercem mandatos de cinco anos no Parlasul estabelecido por um Protocolo Constitutivo que prevê mandatos de quatro anos. O quarto elemento parece positivo, na medida em que se reconhece a possibilidade de mudança nas regras para atender novas determinações oriundas do Mercosul, o qual deixa espaço para adequações à implementação do Dia do Mercosul Cidadão.

$\mathrm{O}$ quadro a seguir sumariza o processo do caso paraguaio, explicitado anteriormente.

Quadro 1: Paraguai e sua legislação eleitoral para eleições diretas de representantes ao Parlasul 


\begin{tabular}{|c|c|c|c|}
\hline Ley & Elecciones y candidatos & $\begin{array}{l}\text { Distribución de los } 18 \\
\text { representantes }\end{array}$ & $\begin{array}{l}\text { Sistema de } \\
\text { elección }\end{array}$ \\
\hline Ley 834/96 & $\begin{array}{l}\text { Elecciones simultáneas (artículo } \\
248, \text { modificado por la ley } \\
3166 / 07 \text { ) } \\
\text { Art. 246 (modificado por la ley } \\
3166 / 07 \text { ): } \\
\text { Son elegibles para desempeñarse } \\
\text { como senadores, diputados y } \\
\text { parlamentarios del Mercosur, los } \\
\text { que hallándose en ejercicio de su } \\
\text { derecho de sufragio pasivo reúnan } \\
\text { las condiciones establecidas en la } \\
\text { Constitución Nacional y no se } \\
\text { hallen comprendidos en las } \\
\text { inhabilidades establecidas en la } \\
\text { misma. }\end{array}$ & $\begin{array}{l}\text { Art. } 247 \text { segunda parte } \\
\text { (modificado por la ley } 3166 / 07 \text { ): } \\
\text { Los parlamentarios del } \\
\text { MERCOSUR serán electos por el } \\
\text { sistema de lista completa y de } \\
\text { representación proporcional, de } \\
\text { acuerdo con los términos del } \\
\text { Artículo } 258 \text { de este código. }\end{array}$ & $\begin{array}{l}\text { Lista } \\
\text { completa } \\
\text { Los escaños } \\
\text { se } \\
\text { distribuyen } \\
\text { conforme el } \\
\text { sistema } \\
\text { D'Hont }\end{array}$ \\
\hline
\end{tabular}

\begin{tabular}{|l|l|l|l|}
\hline $\begin{array}{l}\text { Resoluciones } \\
\text { del TSJE }\end{array}$ & Elecciones simultáneas a las & & \\
$\mathbf{5 5 / 0 7}$ & presidenciales y de legisladores & & \\
$\mathbf{( 2 0 / 0 8 / 0 7}$ y & salvo modificaciones que pudieren & & \\
$\mathbf{2 0 / 0 4 / 0 8 )}$ & surgir por el CMC y de & & \\
\hline $\begin{array}{l}\text { Resolución } \\
\text { del TSJE }\end{array}$ & constitutivo & & \\
$\mathbf{6 5 / 1 3}$ & Convocatoria a elecciones & & \\
& Senerales para Presidente, Vice, & & \\
& Parlamentarios del MERCOSUR y & & \\
& miembros de Juntas & & \\
& Departamentales para el 21/04/13 & & \\
\hline
\end{tabular}

Fonte: Gajate; Saca (2015, p. 69).

No que concerne à Argentina, o país elegeu diretamente seus representantes regionais em 2015 após a proposição e aprovação de um projeto de lei em um processo que durou pouco mais de um mês (entre 3 de dezembro de 2014 e 6 de janeiro de 2015), período muito inferior à apresentação e discussão de todos os projetos apresentados às eleições do Parlasul (entre os anos de 2008 e 2014).

Foram trinta e seis projetos de lei apresentados pelas duas Casas do Legislativo argentino, que podem ser organizados, de acordo com Luciano (2014), em três diferentes grupos mediante ao sistema proposto para a votação: misto, composto por projetos que propunham duas listas de votação, uma por províncias com seleção majoritária e outra com nacional com seleção proporcional; modelo único, propondo lista única nacional com representação proporcional; e regional, que reorganizava as províncias em distritos para as votações. O quadro a seguir trata da totalidade dos projetos apresentados pelos grupos políticos Frente Para la Victoria (FPV), Una Nueva Alternativa (UNA), Compromiso Federal, Cambiemos e Frente Progresista. 
Quadro 2: os projetos de eleição ao Parlasul na Argentina

\begin{tabular}{|c|c|c|c|c|c|c|c|c|c|c|c|c|c|c|c|c|c|c|c|c|c|c|}
\hline \multirow{3}{*}{ Partido } & \multicolumn{21}{|c|}{ Ano de apresentação e sistema de representação proposto } & \multirow{3}{*}{\begin{tabular}{|c} 
Total \\
por \\
partido
\end{tabular}} \\
\hline & \multicolumn{3}{|c|}{2008} & \multicolumn{3}{|c|}{2009} & \multicolumn{3}{|c|}{2010} & \multicolumn{3}{|c|}{2011} & \multicolumn{3}{|c|}{2012} & \multicolumn{3}{|c|}{2013} & \multicolumn{3}{|c|}{2014} & \\
\hline & Regional & Único & Misto & Regional & Único & Misto & Regional & Único & Misto & Regional & Único & Misto & Regional & Único & Misto & Regional & Único & Misto & Regional & Único & Misto & \\
\hline FPV & & & 1 & & 1 & 2 & & 1 & ${ }^{*} 2$ & & 1 & 1 & & & 1 & & 1 & & 1 & & 4 & 16 \\
\hline UNA & & & & & & & & & 1 & & & & & & & & & & 2 & 1 & 2 & 6 \\
\hline $\begin{array}{c}\text { Compromiso } \\
\text { Federal }\end{array}$ & & 1 & & & & 1 & & & $\stackrel{*}{* *} 2$ & & & & & & & & & & & & & 4 \\
\hline Cambiemos & & & & & & & 1 & 2 & ${ }^{* *} 1$ & 1 & 1 & & & & 1 & & & & 1 & 2 & & 10 \\
\hline $\begin{array}{c}\text { Frente } \\
\text { Progresista }\end{array}$ & & & & & & & & & & & & & 1 & & & & & & & 1 & & 2 \\
\hline \multirow{2}{*}{$\begin{array}{l}\text { Total } \\
\text { geral }\end{array}$} & & 1 & 1 & & 1 & 3 & 1 & 3 & 4 & 1 & 2 & 1 & 1 & & 2 & & & & 4 & 4 & 6 & \multirow{2}{*}{${ }^{* * *} 36$} \\
\hline & \multicolumn{3}{|c|}{2} & \multicolumn{3}{|c|}{4} & \multicolumn{3}{|c|}{8} & \multicolumn{3}{|c|}{4} & \multicolumn{3}{|c|}{3} & \multicolumn{3}{|c|}{1} & \multicolumn{3}{|c|}{14} & \\
\hline
\end{tabular}

* O mesmo projeto foi apresentado por parlamentares das duas siglas

** O mesmo projeto foi apresentado por parlamentares das duas siglas

*** Foram descontados 2 projetos na coluna Total por partido porque foram apresentados simultaneamente por duas siglas

Fonte: Baseado em diversas fontes.

Somente um projeto foi apresentado por um parlamentar com mandato nacional e no Parlasul (por indicação). Alberto Asseff, da UNA, foi o único parlamentar de mandato duplo a apresentar projeto de lei à regulamentação das eleições da integração. É um número muito baixo, considerando que a Argentina tem a segunda maior delegação do Parlasul e que essas proposições começaram no ano de 2008. Asseff também foi posteriormente eleito ao Parlasul completando, ao lado de Agustín Oscar Rossi e Julia Argentina Perié (FPV), o grupo dos três parlamentares eleitos diretamente que tinham sido parlamentares indicados no Parlasul.

As eleições ao Parlasul na Argentina foram possíveis pela implementação da lei $\mathrm{n}^{\mathrm{o}} 27.120$ de 2015. Esta teve origem no projeto de lei $\mathrm{n}^{\mathrm{o}}$ 0134-D-2014, de autoria do então deputado Jorge Landau (FPV). Inicialmente, o projeto foi apresentado em comissões da Câmara dos Deputados em 03 de dezembro de 2014, sendo aprovado pela Câmara em 16 de dezembro. O projeto seguiu para comissões do Senado, sendo aprovado em sua última sessão do ano, em 30 de dezembro. A oposição questionou a rapidez com que o projeto seguiu, acusando de ser uma tentativa de propiciar a candidatura de Cristina Kirchner ao Parlasul e conferir-lhe, se eleita, foro especial.

Não por acaso, o projeto se utilizou de estratégia similar àquela da aprovação do Protocolo Constitutivo do Parlasul. Os temas controversos e que haviam sido consensuados ou debatidos satisfatoriamente foram deixados de lado, a prioridade foi estabelecer as eleições diretas à integração, sendo que as outras questões pendentes seriam posteriormente adequadas no Congresso Nacional por outras legislações. 
Por esse motivo, a delegação argentina no Parlasul não recebe salários, não tem locais de reunião e assessorias na esfera doméstica (apenas o espaço de uma reunião ordinária mensal no Parlasul em plenário) e não tem definidos os mecanismos de diálogo e interação com o Congresso Nacional. Esse limbo no qual a delação encontrase é resultado de um frustrado cálculo político do FPV, que previa a vitória na disputa à presidência e uma maioria ampliada no Congresso Nacional. Essas pendências seguem sem solução próxima.

O quadro três trata do sistema eleitoral adotado pela lei nº 27.120 .

Quadro 3: sistema adotado pela lei 27.120

\begin{tabular}{|c|c|c|}
\hline $\begin{array}{l}\text { Elecciones } \\
\text { candidatos }\end{array}$ & $\begin{array}{l}\text { Distribución de los } 43 \\
\text { representantes }\end{array}$ & Sistema de elección \\
\hline $\begin{array}{l}\text { Elecciones simultáneas } \\
\text { con las generales } \\
\text { presidenciales y de } \\
\text { legisladores nacionales }\end{array}$ & $\begin{array}{l}24 \text { por cada una de las } \\
\text { provincias y la CABA } \\
19 \text { distrito único a nivel } \\
\text { nacional y distribuidos } \\
\text { entre las diferentes } \\
\text { fuerzas }\end{array}$ & $\begin{array}{ll}\text { Mixto } & \\
\text { Distribución por el } \\
\text { sistema } \\
\text { representación } \\
\text { proporcional (D'Hont) }\end{array}$ \\
\hline
\end{tabular}

Fonte: Gajate; Saca (2015, p. 75).

As eleições ao Parlasul ocorrem simultaneamente às nacionais para eleger quarenta e três assentos, sendo vinte e quatro por voto majoritário nas províncias e na Capital Buenos Aires e os dezenove restantes por representação proporcional D'Hont em distrito nacional único. A lei trata as eleições ao Parlasul enquanto Dia do Mercosul Cidadão, observando que são simultâneas às eleições gerais enquanto não são realizadas simultaneamente em todos os países-membros do bloco. Além das eleições primárias (PASO), há uma cota de 30\% de mulheres na lista, mas essas regras já eram aplicadas nacionalmente.

Sobre essas eleições, é possível apontar que "há sobre e sub-representarão evidente: um parlamentar por Terra do Fogo representa 152.317 habitantes, enquanto que 1 e Buenos Aires, por pluralidade simples, representa mais de 16 milhões de habitantes" (GAJATE; SACA, 2015 p. 76). Além disso, "é evidente também que o representante eleito pelo sistema de distrito nacional, especialmente quem ocupe o primeiro lugar da lista, terá uma força única, uma legitimidade que até agora o sistema eleitoral só outorgava ao cargo de presidente e vice" (GAJATE; SACA, 2015 p. 77).

Apesar de as regiões estarem todas representadas, um representante por 
província é desproporcional à população por ele representada. Além disso, a lista nacional não apresenta mecanismos de proporcionalidade regional, favorecendo que figuras do alto escalão político nacional possam encabeçar as listas como puxa votos, secundarizando a importância dos demais nomes apresentados. Assim como no Paraguai, as eleições ao Parlasul na Argentina estão atreladas a todo o contexto de disputa política e eleitoral nacional.

\section{AS ELEIÇÕES AO PARLASUL NO PARAGUAI E NA ARGENTINA}

Poucos foram aqueles que participaram da CPC e do Parlasul por indicação e retornaram ao Parlamento como eleitos. Na Argentina, Alberto Asseff (UNA), Agustín Oscar Rossi e Julia Argentina Perié (FPV) foram os únicos parlamentares eleitos que já haviam sido indicados ao Parlasul, os três por lista única nacional. O Paraguai, por sua vez, teve parlamentares que passaram tanto pela CPC quanto pelo Parlasul por indicações, com destaque aos parlamentares Gonzalez Nuñez (ANR) e Luis Guggiari (PLRA), que participaram das negociações do Protocolo Constitutivo do Parlasul, sendo que Nuñez foi que propôs a reforma eleitoral que resultou na lei às eleições ao Parlasul no Paraguai. O quadro seguinte trata dessas experiências prévias.

\section{Quadro 4: Eleitos com experiência prévia na CPC e/ou no Parlasul por indicação}




\begin{tabular}{|c|c|c|c|}
\hline & $\begin{array}{c}\text { Eleitos pelo Paraguai em } \\
2008\end{array}$ & $\begin{array}{l}\text { Eleitos pelo Paraguai em } \\
\qquad 2013\end{array}$ & $\begin{array}{l}\text { Eleitos pela Argentina em } \\
\qquad 2015\end{array}$ \\
\hline Participação prévia na CPC & $\begin{array}{l}\text { Alfonso Gonzalez Nuñez } \\
\text { (ANR - Colorado) } \\
\text { Angel Ramon Barchini } \\
\text { Cibils (ANR - Colorado) } \\
\text { Atilio Martinez Casado } \\
\text { (PLRA) } \\
\text { Hector Lacognata (PPQ) }\end{array}$ & $\begin{array}{l}\text { Alfonso Gonzalez Nuñez } \\
\text { (ANR - Colorado) } \\
\text { Miguel Angel Gonzales } \\
\text { Erico (PLRA) }\end{array}$ & $*$ \\
\hline $\begin{array}{l}\text { Particip ou previamente do } \\
\text { Parlasul como indicado }\end{array}$ & $\begin{array}{l}\text { Alfonso Gonzalez Nuñez } \\
\text { (ANR - Colorado) 2006- } \\
2008 \\
\text { Modesto Luis Guggiari } \\
\text { Zabala (PLRA) 2006-2008 } \\
\text { Héctor Lacognata (PPQ) } \\
\text { 2006-2008 }\end{array}$ & $\begin{array}{l}\text { Crescencio Herminio } \\
\text { Caceres Santacruz (ANR - } \\
\text { Colorado) 2006-2008 } \\
\text { Alfonso Gonzalez Nuñez } \\
\text { (ANR - Colorado) 2006- } \\
2008\end{array}$ & $\begin{array}{l}\text { Alberto Emilio Asseff } \\
\text { (UNA) 2013-2014 } \\
\text { Agustin Oscar Rossi (FPV) } \\
2005-2009 \\
\text { Julia Argentina Perié (FPV) } \\
\text { 2007-2011 e 2013-2015 }\end{array}$ \\
\hline
\end{tabular}

* Jorge Taiana (FPV) é firmante de um documento na CPC, mas o fez enquanto ministro de Estado de Néstor Kirchner

Fonte: Baseado em diferentes fontes.

A proximidade construída entre partidos e parlamentares às temáticas da integração regional foram importantes para os resultados eleitorais, que pôde ser mais evidenciado na Argentina. No Paraguai, a ANR e o PLRA são os dois partidos majoritários. Tendo em vista que as eleições ao Parlasul foram incorporadas ao cenário de disputas eleitorais nacionais, esses dois partidos conquistaram amplas maiorias no número de assentos nas duas eleições regionais. No entanto, ao contrário da Argentina, houve maior aproveitamento de parlamentares que já haviam participado da CPC e do Parlasul enquanto indicados, estes também ocuparam as primeiras posições das listas de seus partidos.

Essa relação parece mais relevante para as eleições de 2008, quando Héctor Lacognata foi o único candidato do Partido Pátria Querida (PPQ) a ser eleito para o Parlasul. Outro candidato que foi o único de seu partido a conseguir assento foi Ricardo Canese, do Movimento Popular Tekojoja (MPT, posteriormente integrante da Frente Guasú, FG) que, apesar de não ter as experiências prévias em questão, tem participação ampla em debates fronteiriços em relação à Usina Hidrelétrica Binacional de Itaipu. $\mathrm{O}$ restante dos eleitos integrava um grupo dissidente da ANR, a UNACE.

Em relação a reeleições, seis parlamentares receberam um segundo mandato por eleição em 2013. São eles: Alfonso Gonzalez Nuñez e Zacarias Ernesto Vera 
Cardenas (ANR), Amanda Rosalia Nuñez Sanchez e Mirtha Elizabeth Palacios Melgarejo (PLRA), Ricardo Nicolas Canese Krivoshein (MPT e FG), Ramon Roberto Dominguez Santacruz (UNACE).

O quadro 5 agrega informações da distribuição dos dezoito assentos paraguaios no Parlasul por grupos políticos nas eleições de 2008 e 2013.

Quadro 5: Distribuição de assentos das delegações paraguaias no Parlasul (eleições de 2008 e 2013)

\begin{tabular}{|c|c|c|c|}
\hline Partido & Eleições 2008 & Eleições 2013 & Total por partido \\
\hline ANR & 6 & 10 & $\mathbf{1 6}$ \\
\hline PLRA & 6 & 6 & $\mathbf{1 2}$ \\
\hline FG & 1 & 1 & $\mathbf{2}$ \\
\hline PPQ & 1 & 0 & $\mathbf{1}$ \\
\hline UNACE & 4 & 1 & $\mathbf{5}$ \\
\hline Total geral & $\mathbf{1 8}$ & $\mathbf{1 8}$ & $\mathbf{3 6}$ \\
\hline
\end{tabular}

Fonte: Baseado em resultados oficiais.

As eleições ao Parlasul na Argentina mostraram o prestígio do FPV em relação ao órgão, que também guarda uma relação próxima ao legado kirchnerista. Inclusive, a oposição do Cambiemos questionava se o projeto de lei eleitoral ao Parlasul não seria uma tentativa de resguardar Cristina Kirchner de possíveis processos judiciais no país considerando que, se eleita, poderia ter alguma imunidade.

Além disso, a oposição também calculava que Cristina seria uma candidata para o topo da lista nacional do FPV ao Parlasul, impulsionando a sigla. Apesar dessa candidatura não ter sido concretizada, a oposição apostou em uma campanha eleitoral com temática regional baseada em dois eixos: o rechaço do legado kirchnerista e a necessidade de fazer da integração no Mercosul um espaço de abertura ao mundo, especificamente aos grandes acordos econômicos do Pacífico, União Europeia, China e Estados Unidos. Pela UNA, Alberto Asseff, que já havia participado do Parlasul, foi um dos eleitos, mas figurava apenas como terceiro da lista do partido.

Apesar da disputa acirrada na eleição por distrito nacional único, o FPV conseguiu uma ampla vitória nas eleições ao Parlasul por províncias. Considerando que a população de uma minoria das províncias tenha uma relação mais imediata com debates públicos sobre o Mercosul, o prestígio kirchnerista e do FPV foram um fator 
importante para seus triunfos eleitorais, especialmente em virtude de que o candidato à presidência, Daniel Scioli, perdeu as eleições.

O quadro 6 apresenta a distribuição de assentos no Parlasul pelos resultados das eleições na Argentina em 2015.

Quadro 6: Distribuição de assentos da delegação argentina no Parlasul (eleições de 2015)

\begin{tabular}{|c|c|c|c|}
\hline Partido & Distrito Nacional Único & Por Províncias e Capital & Total por partido \\
\hline FPV & 8 & 18 & $\mathbf{2 6}$ \\
\hline Cambiemos & 7 & 5 & $\mathbf{1 2}$ \\
\hline UNA & 4 & 0 & $\mathbf{4}$ \\
\hline Compromiso Federal & 0 & 1 & $\mathbf{1}$ \\
\hline Total geral & $\mathbf{1 9}$ & $\mathbf{2 4}$ & $\mathbf{4 3}$ \\
\hline
\end{tabular}

Fonte: Baseado em resultados oficiais.

\section{CONSIDERAÇÕES}

As eleições diretas ao Parlasul, realizadas apenas pelo Paraguai e pela Argentina, ainda não conseguiram estabelecer de fato um debate acerca das temáticas da integração regional. O processo eleitoral construído revela uma priorização das disputas partidárias e políticas internas, o que não invalida uma relação entre o processo da integração e determinados grupos e indivíduos. Os partidos políticos que se mantiveram mais próximos à integração no Mercosul e à formação do Parlasul conseguiram consolidar certo prestígio nos debates nacionais sobre os debates regionalistas.

O legado da CPC e das bancadas indicadas ao Parlasul possui mais uma relação de participação do que de causa e consequência direta nas eleições, visto que não são muitos os candidatos que participaram desses dois momentos da representação parlamentar na integração. Tendo em vista que a Argentina realizou essas eleições apenas uma vez, é difícil imaginar de que forma estas influenciarão nas próximas. No entanto, o Paraguai demonstrou uma possibilidade de continuidade nesse sentido, uma vez que um terço dos 18 parlamentares foi reeleito para segundo mandato, indicando que nas eleições regionais, apesar de estarem num quadro de disputa ligado àquele da esfera nacional, os parlamentares regionais passaram a ter alguma vantagem em novas disputas ao Parlasul. 
É importante destacar que a assimilação de determinações da integração passa justamente pelo cálculo político da conjuntura nacional, especialmente das disputas eleitorais. Enquanto a ANR, do Paraguai, adequou sua legislação eleitoral para garantir o piso de dezoito assentos no Parlasul, também buscava maior projeção política, visto que o partido sofreu dissidência, perdeu a aliança com o PLRA para a disputa do Executivo nacional e não tinha um candidato à presidência que pudesse fazer frente a Fernando Lugo.

A Argentina também mostrou fortes determinações da conjuntura doméstica para realização de sua adequação eleitoral. A sucessão kirchnerista contaria com o espaço do debate ao Parlasul para fortalecer suas candidaturas, especialmente a candidatura de Daniel Scioli à presidência. O FPV conseguiu aproveitar seu prestígio junto ao Parlasul nas eleições regionais por província, mas não foi o suficiente para as vitórias que o partido esperava em 2015, tanto no Executivo quanto no Legislativo nacionais. Como consequência, a maioria do FPV no Parlasul ainda sofre com as brechas da lei 27.120, ao passo que a mobilização no Congresso Nacional não é suficiente para terminar as controvérsias em torno da representação do país na integração.

As adequações legislativas nos dois países preveem a conformação do Dia do Mercosul Cidadão, mas as modificações necessárias não parecem de fácil implementação, especialmente no caso paraguaio, uma vez que as eleições ocorrem a cada 5 anos, sendo necessária uma revisão de toda a regulamentação eleitoral nacional para o pleno atendimento das prerrogativas do Protocolo Constitutivo do Parlasul.

Em relação a esse documento, em ambos os países as eleições regionais não houve implementações específicas para que as candidaturas postuladas reapresentassem de fato uma figura média do contexto plural do país como um todo. Apesar da cota feminina nas eleições argentinas, esse mecanismo já era aplicado e, a depender da combinação com os resultados provinciais das eleições ao Parlasul, pode surtir efeitos quase nulos. Ambos os países promoveram adequações insuficientes no combate a sub e sobrerrepresentações diversas no Parlasul.

Finalmente, o artigo pôde combinar fatores domésticos a um histórico de desenvolvimento institucional e engajamentos políticos na representação parlamentar no Parlasul, todos combinados na conformação de eleições diretas à integração, que é 
justamente o início da conformação de um parlamento regional mais representativo e legítimo, que ainda trilha caminhos para sua plenitude e unificação na conformação do Dia do Mercosul Cidadão.

\section{REFERÊNCIAS}

BRESSAN, R. N. MARIANO, K. L. P. LUCIANO, B. T. Parlamentos Regionais na América Latina em estudo comparado. In: ST 05 Experiências de participação institucional em perspectiva comparada. 2015, Campinas. II Encontro Internacional Participação, Democracia e Políticas Públicas, Campinas, 2015, p. 1-19.

CAPORASO, J. A. Regional integration theory: understanding our past and anticipating our future. Journal of European Public Policy, n.5, p. 1-16. 1998.

CASTRO, A. C. B. Os bancos de desenvolvimento e a integração da América do Sul: bases para uma política de cooperação. Brasília: Fundação Alexandre de Gusmão, 2011.

CEPAL, América Latina y el Caribe: políticas para mejorar su inserción en la economía mundial. Santiago de Chile, 1994.

DRUMMOND, M. C. Representación Ciudadana en el Parlamento del Mercosur: la construcción del acuerdo político. Puente @ Europa, ano XII, dezembro, 2009.

A Democracia Desconstruída. O deficit democrático nas relações internacionais e os parlamentos da integração. Brasília: Senado Federal, Subsecretaria de Edições Técnicas, 2010.

GAJATE, R. M. SACA, J. C. F. Elección de parlamentarios para el MERCOSUR. Avances en la constitución del PARLASUR. La experiencia PARLACEN. Revista Aportes para la Integración Latinoamericana, Año XXI, N 32/Junio 2015, p. 54-91, 2015.

HABERMAS, J. Democracia, Solidariedade e a Crise Europeia. In. CONFERENCIA NA UNIVERSIDADE CATÓLICA DE LEUVEN, 2013, Bélgica. Disponível em https://gestaoculturalesad.files.wordpress.com/2013/04/democracia-solidariedade-ecrise-europeia.pdf. Acessado em 23 de junho de 2017. 
HURRELL, A.. O Ressurgimento do Regionalismo na Política Mundial. Contexto Internacional. V. 17, n. 1. p. 23-59, 1995.

KINOSHITA, F. Da Associação Latino-Americana de Livre Comércio à Associação Latino-Amercana de Integração: Notas sobre a integração regional. In: Âmbito Jurídico, fevereiro, 2002. Disponível em http://www.ambitojuridico.com.br/site/index.php?n_link=revista_artigos_leitura\&artig o_id=5586. Acessado em 20 de junho de 2017.

LUCIANO, B. T. A inclusão da representatividade direta no Parlamento do Mercosul, Boletim de Economia e Política Internacional. n.11 julho/setembro. 2012, p. 49-58.

LUCIANO, Bruno Theodoro. Eleições na integração regional: desenvolvimento das proposições nacionais para as eleições diretas do Parlamento do MERCOSUL, Revista E-legis, Brasília, n. 13, jan./abr. 2014, p. 57-72.

LUCIANO, B. T. MARIANO. K. L. P. Implicações nacionais da integração regional: as eleições diretas do Parlamento do Mercosul. Perspectivas, v.42. São Paulo, p.41-77. 2012.

MAIRA, L. La evaluación de la diplomacia. In: LAGLER, Thomas; SANTA CRUZ, Arturo; GONZALES, Laura Z. (Org). Introducción a las Relaciones Internacionales: América Latina y Política Global. Oxford University Press, 2013.

MALAMUD, A. SOUSA, L. Parlamentos Supranacionais na Europa e na América Latina: Entre o Fortalecimento e a Irrelevância. Contexto Internacional, n.27. Rio de Janeiro. p.369-409. 2005.

MARIANO, K. L. P. A eleição parlamentar no Mercosul. Revista Brasileira de Política Internacional, 54 (2): p.138-157 [2011].

2013.

. Parlamento do Mercosul. Século XXI, v. 4, n.2. Porto Alegre.

PARLAMENTO DO MERCOSUL. Protocolo constitutivo do Parlamento do Mercosul, 2005. Disponível em: <http://www.parlamentodelmercosur.org/innovaportal/file/7555/1/protocolo_pt.pdf > Acesso em 24 de junho de 2017. 
PIETRAFESA, Pedro Araújo. A construção de uma nova instituição parlamentar no Cone Sul: o Parlamento do Mercosul. 2009. 119 f., il. Dissertação (Mestrado em Estudos Comparados)-Universidade de Brasília, Brasília, 2009.

Recebido em 03/08/2017. Aceito em 01/12/2017. Publicado em 29/12/2017.

DOI: 10.11606/issn.1676-6288.prolam.2017.134272 ISSN: $1676-6288$ 